University of Zurich

Department of Economics

Working Paper Series

ISSN 1664-7041 (print)

ISSN 1664-705X (online)

Working Paper No. 73

\title{
Expectations as Reference Points: Field Evidence from Experienced Subjects in a Competitive, High-Stakes Environment
}

Björn Bartling, Leif Brandes and Daniel Schunk

May 2012 


\title{
Expectations as Reference Points:
}

\section{Field Evidence from Experienced Subjects in a}

\section{Competitive, High-Stakes Environment*}

\author{
Björn Bartling ${ }^{\text {a) }}$, Leif Brandes ${ }^{\text {b) }}$, and Daniel Schunk ${ }^{\text {c) }}$
}

May 7, 2012

\begin{abstract}
We show that professional soccer players exhibit reference-dependent behavior during matches. Controlling for the state of the match and for unobserved heterogeneity, we show on a minute-by-minute basis that a player breaches the rules of the game, measured by the referee's assignment of cards, with a significantly higher probability if his team is behind the expected match outcome, measured by pre-play betting odds of large professional bookmakers. We derive these results in two independent data sets, one from ten seasons of the German Bundesliga, the other from eight seasons the English Premier League, each with more than half a million minutes of play.
\end{abstract}

JEL classification: D03, D81, D84, L83

Keywords: reference points, expectations, experience, high stakes, competition

\footnotetext{
* We would like to thank seminar participants at the University of Zurich, the Economic Science Association World Meeting in Copenhagen 2010, the Nordic Conference on Behavioral and Experimental Economics in Helsinki 2010, the International Meeting on Experimental and Behavioral Economics in Barcelona 2011, and the Royal Economic Society Meeting in London 2011 for helpful comments and suggestions. Nicolai Grüter and Tizoc José Bachmann provided excellent research assistance.

a) Björn Bartling, Department of Economics, University of Zurich, Blümlisalpstrasse 10, 8006 Zurich, Switzerland, e-mail: bjoern.bartling@econ.uzh.ch

b) Leif Brandes, Department of Business Administration, University of Zurich, Plattenstrasse 14, 8032 Zurich, Switzerland, email: leif.brandes@,business.uzh.ch

c) Daniel Schunk, Department of Economics, University of Mainz, Saarstraße 21, 55099 Mainz, Germany, e-mail: daniel.schunk@uni-mainz.de
} 


\section{Introduction}

Reference-dependent preferences are an active area of research. The key idea is that a person's assessment of an outcome is determined not only by the outcome itself but also by its contrast with a reference point (Kahneman and Tversky 1979). An important open question in the literature is what determines the reference point. A growing number of theoretical contributions (e.g., Bell 1985, Loomes and Sugden 1986, Gul 1991, Köszegi and Rabin 2006, 2007, 2009) model reference points as shaped by expectations. Direct tests of these models using field data are difficult, however, because "expectations are hard to observe in the field" (Abeler et al., 2011, p. 470). In this paper, we report on two unique, naturally-occurring panel field data sets that allow exactly this: to observe (i) an exact quantitative measure of people's ex-ante expectations, (ii) their current outcome relative to their expectation, and (iii) an objective measure of behavior over time.

Understanding the determinants of reference points and their consequences for behavior is of vital importance in organizational and managerial decision making. As one field of application, consider the impact of reference points on worker morale and effort choices. Bewley (1999), for example, reports evidence from interviews with over three hundred professionals, such as business executives, labor leaders, and professional recruiters that workers compare current earnings to previous earnings and that wage cuts undermine work morale. The reason might be that previous earnings serve as an expectationbased reference point for current earnings, and that workers dislike falling short of this reference point. In a more recent field study, Ockenfels et al. (2010) investigate how bonus payments affect managers' satisfaction and performance in a large, multinational company. They show that bonus payments falling short of individually assigned bonus targets reduce satisfaction and subsequent performance. Again, the bonus target is likely to be the expected bonus, i.e., an expectation-based reference point. ${ }^{1}$ Other fields of

\footnotetext{
${ }^{1}$ Similarly, Camerer et al. (1997), Mas (2006), Fehr and Goette (2007), Crawford and Meng (2011), and Pope and Schweitzer (2011), among others, show the influence of expectation-based reference points on effort choices by cab drivers, police officers, bicycle messengers, and professional golfers. Field evidence of expectation-based reference points in domains other than effort provision is provided by, e.g., Loomes and Sugden (1987), Choi et al. (2007), and Post et al. (2008), who study choices over lotteries. Card and Dahl (2011) show the effect of unexpected emotional cues, such as the unexpected loss of an NFL football team on domestic violence.
} 
application that are relevant for organizational and managerial decision making include the effect of reference-dependent preferences on optimal consumer goods pricing (e.g., Heidhues and Köszegi 2008) and incomplete contracting (e.g., Hart and Moore 2008, Herweg et al. 2011). Despite the growing importance of reference points in the economics literature in general and for organizational and managerial decision making in particular, clean field evidence on the determinants of references points and on the influence of reference points on behavior is still relatively scarce. ${ }^{2}$

In this paper, we use two independent data sets from two leading soccer leagues, the German Bundesliga and the British Premier League, to show that professional soccer players' behavior during matches depends significantly on whether or not their team is behind the expected match outcome. Large professional bookmakers' pre-play betting odds on match outcomes allow us to construct an exact measure of the players' expectations. Our behavioral measure is the players' breaches of the rules of the game, such as fouling a player of the opposing team, measured by "cards" that are shown for irregular behavior to individual players by highly trained, impartial referees.

We find that if a team is behind the expected match outcome (e.g., the state of the match is a tie or the team is behind, while the pre-play expectation was to win the match), the players of this team see significantly more cards compared to situations in which the team is not behind its expectation (e.g., the state of the match is a tie and the team expected to tie or to lose). This finding holds when we control for the state of the match as well as for unobserved match and team specific heterogeneity. The size of the effect is large: if a team is behind its expected match outcome, the probability that a player of that team will see a card in a given minute is increased by more than 20 percent in our sample from the German Bundesliga, and it is increased by even 30 percent in our sample from the British Premier League. These findings lend support to the idea that expectations shape reference points and that people's behavior depends on how a given outcome contrasts with this reference point.

\footnotetext{
${ }^{2}$ In laboratory settings, it is easier to experimentally control reference points. Recent laboratory studies showing the importance of expectation-based reference points include Abeler et al. (2011) who exogenously influenced subjects' earnings expectations. They show that if expectations are high, subjects work longer and earn more money than if expectations are low. Marzilli Ericson and Fuster (2011) find that the valuation placed on an endowed good depends on the probability that a trading opportunity will arise. Gill and Prowse (2012) find that subjects have reference points given by their expected monetary payoff in a tournament and that a subject's reference point adjusts essentially instantaneously to his own effort choice and to that of his competitor.
} 
It is noteworthy that our field data not only comes from professional, experienced subjects who act in their natural environment but, in addition, from a fiercely competitive industry that involves very high stakes. It is sometimes argued (e.g. Levitt and List, 2007) that behavioral "anomalies" observed in laboratory settings, where subjects make decisions in artificial situations and with relatively low stakes, will disappear in real-world contexts with experienced subjects, competition, or high stakes. ${ }^{3}$ Our data clearly show that the behavioral "anomaly" of reference-dependent behavior neither disappears with experience, competition, nor in a high-stakes environment.

\section{Institutional background on soccer and leagues}

A soccer team consists of 11 players, one of whom must be a goalkeeper. Two teams compete to kick the ball into the other team's goal. The primary rule is that players are not allowed to handle the ball with their hands or arms. The team that has scored more goals at the end of a match is the winner; the match is a tie if both teams have scored an equal number of goals. In order to determine league standings, the winning team receives 3 points; the losing team receives 0 points. If the match is a tie, teams receive 1 point each. A match is officiated by a referee, whose decisions are final. Matches are played in two halves of 45 minutes each, but total playing time regularly exceeds 45 minutes in each half (typically by 1 to 3 minutes) due to the addition of injury time by the referee.

A foul occurs when a player violates the rules of the game. Most often, a player's misconduct consists of tripping or pushing an opponent. Such misbehavior is sanctioned by the referee with the assignment of a yellow card or a red card. The first yellow card for a player in a match is a caution, which is shown for a clear offence. The second yellow card for a player in the same match, however, results in being sent off the field —in which case the player's team will continue with only 10 players. A red card is shown for serious foul play such as violent conduct. In these cases, which are very rare, the player must also leave the field immediately. Moreover, the sanctioned player is suspended from at least the next match, sometimes from several ones.

\footnotetext{
${ }^{3}$ See Falk and Heckman (2009) for the comparative advantages of laboratory experiments.
} 
The German Bundesliga (henceforth BL) is the number one European soccer league in terms of weekly attendance figures, and it is the second most important league in terms of revenues and profitability. For example, the league generated revenues of about 1.4 billion EUR in the 2007/08 season, resulting in profits of about 136 million EUR (Deloitte, 2009). The BL consists of 18 teams that compete with each other for winning the German championship (that is, to become the team with the highest number of points at the end of the season), qualifying for international competitions, such as the UEFA Champions League, and for avoiding relegation. ${ }^{4}$ Each BL team plays every other team twice every season, where one match is played at the team's home field and the other at the competitor's field. At the end of the season, each team will thus have played 34 matches.

The English Premier League (henceforth PL) is the only European soccer league that is more profitable than the German BL. In the 2007/08 season, the PL generated revenues of 2.4 billion EUR resulting in a profit of 234 million EUR (Deloitte, 2009). The playing schedule in the PL resembles that of the BL, albeit there are 20 teams in the PL. Hence, at the end of the season, each team will have played 38 matches.

\section{Data}

Our data contains information on all 3'060 matches in the BL during the ten seasons from 1998/99 to 2007/08. ${ }^{5}$ For each match, we have detailed minute-by-minute information on goals and cards. Table 1 contains summary statistics for goals, cards (yellow and red cards combined), yellow cards, and red cards on a match and on a minute basis. Altogether, 8’719 goals were scored and 13'432 cards shown. The average number of goals per match is slightly less than three, which corresponds to 0.015 goals per minute per team. With respect to the cards, we find red cards to be very rare events relative to yellow cards. On the match level, the average number of yellow and red cards is 4.29 and 0.10 , respectively.

\footnotetext{
${ }^{4}$ This latter aspect distinguishes the league from most U.S. sports leagues, which are closed leagues. In the BL, the three worst performing teams are replaced by the top teams from the next lower league at the end of each season.

${ }^{5}$ One reason for the increasing usage of sports data sets in economic research is that they provide statistics that "are much more detailed and accurate than typical microdata samples" (Kahn 2000, p. 75). Examples include Walker and Wooders (2001), Chiappori et al. (2002), Kocher and Sutter (2004), Garicano et al. (2005), Dohmen (2008), Price and Wolfers (2010), Pope and Schweitzer (2011), and Kocher et al. (forthcoming).
} 
Table 1: Summary Statistics

German Bundesliga (BL)

English Premier League (PL)

\begin{tabular}{|c|c|c|c|c|c|c|c|c|c|c|}
\hline variable & mean & s.d. & $\min$ & $\max$ & \#obs. & mean & s.d. & $\min$ & $\max$ & \#obs. \\
\hline \multicolumn{11}{|l|}{ per match: } \\
\hline goals & 2.849 & 1.700 & 0 & 11 & 3’060 & 2.579 & 1.649 & 0 & 11 & 3’040 \\
\hline cards & 4.390 & 2.062 & 0 & 15 & 3’060 & 3.240 & 2.061 & 0 & 13 & 3’040 \\
\hline yellow cards & 4.286 & 1.994 & 0 & 13 & 3'060 & 3.139 & 2.014 & 0 & 13 & 3’040 \\
\hline red cards & 0.103 & 0.339 & 0 & 2 & 3’060 & 0.101 & 0.344 & 0 & 4 & 3’040 \\
\hline \multicolumn{11}{|c|}{ per minute and team: } \\
\hline goals & 0.015 & 0.123 & 0 & 2 & $563 ' 988$ & 0.013 & 0.115 & 0 & 2 & $585^{\prime} 178$ \\
\hline cards & 0.024 & 0.154 & 0 & 3 & $563 ’ 988$ & 0.017 & 0.131 & 0 & 3 & $585^{\prime} 178$ \\
\hline yellow card & 0.023 & 0.152 & 0 & 3 & $563 ’ 988$ & 0.016 & 0.128 & 0 & 3 & $585^{\prime} 178$ \\
\hline red cards & 0.001 & 0.024 & 0 & 1 & $563 ’ 988$ & 0.001 & 0.023 & 0 & 2 & $585^{\prime} 178$ \\
\hline loss frame & 0.326 & 0.469 & 0 & 1 & $563^{\prime} 988$ & 0.318 & 0.466 & 0 & 1 & $585^{\prime} 178$ \\
\hline
\end{tabular}

Notes: Displayed are summary statistics for all matches played in the BL in the ten seasons 1998/99 to 2007/08 and all matches played in the PL in the eight seasons from 2000/01 to 2007/08. The number of minutes per match varies according to injury time added by the referee. The stated number of observations for minutes accounts for the fact that we view each match from the perspective of both the home team and the guest team.

Our second sample contains minute-by-minute information on goals and cards for all 3'040 matches in the PL in the eight seasons from 2000/01 to 2007/08. Summary statistics for goals and cards on a match and on a minute basis are displayed in Table 1. Somewhat fewer goals are scored in the PL compared to the BL (2.58 goals per match compared to 2.85), and also fewer cards are assigned (3.24 cards per match compared to 4.39). Red cards are again very rare relative to yellow cards. On the match level, the average number of yellow and red cards is 3.14 and 0.10 , respectively. ${ }^{6}$

In addition to our data on match events, we collected pre-play betting odds from professional bookmakers for each match in our two samples. These data allow us to derive ex-ante expectations of match outcomes. For the BL, we use the betting odds of the German bookmaker ODDSET, one of the largest state-run betting providers in Europe. For the PL, we use the betting odds of Interwetten, one of the leading providers of online betting worldwide. ${ }^{7}$ As an example, consider the match between Hannover

\footnotetext{
${ }^{6}$ The data for the BL and the PL is partly freely available on the internet (apart from, e.g., injury time and assignment of goals to specific minutes in the injury time). The full data set is proprietary and can be obtained from commercial data providers such as Impire (www.bundesliga-datenbank.de/en) for the BL and Press Association Sport (www.pressassociation.com/sport) for the PL. ${ }^{7}$ We obtained the betting odds upon request directly from ODDSET (www.oddset.de). The betting odds of Interwetten can be retrieved on www.football-data.co.uk/.
} 
96 and Mainz 05 from November 5, 2005. The odds from ODDSET for Hannover winning, Mainz winning, and tie, were 1.70, 3.50, and 2.70, respectively. Placing 1 Euro on, say, Hannover winning results in receiving 1.70 Euro if Hannover wins but in losing the Euro otherwise. The odds allow constructing probabilities for each possible match outcome; in our example, the implicit probability of Hannover winning is $0.48 .^{8}$

\section{Hypothesis and estimation method}

In this paper, we test the null hypothesis that a reference point does not affect the players' behavior, measured by assigned cards. Assigned cards measure players' efforts, their risk taking behavior, or their aggressiveness, which all affect the number breaches of the rules of the game, and thus the number of cards assigned. The reference point that we consider is the ex-ante expected match outcome that can be inferred from the pre-play betting odds.

Hypothesis: The reference point defined by the ex-ante expected match outcome does not affect players' behavior.

\subsection{Determination of the reference point}

We derive ex-ante expectations of match outcomes as follows. For each match, we collect the betting odds for all possible match outcomes (home team wins, tie, guest team wins), which imply a probability for each match outcome. To check the predictive power of the betting odds for observed match outcomes, we apply a multinomial logit model. In Appendix A1 we show that the implied probabilities that follow from the betting odds include all relevant information. ${ }^{9}$ Based on the multinomial logit model, we predict a team's most likely match outcome from the betting odds, and we use this prediction of the teams' exante expectation as the reference-point in our regression analysis below.

\footnotetext{
${ }^{8}$ The sum of the inverses of the odds is 1.22 , reflecting the bookmaker's margin. Adjusting the inverse of the betting odd for Hannover winning, $1 / 1.7=0.59$ for this margin results in an implicit probability of $0.59 / 1.22=0.48$.

${ }^{9}$ The hypothesis that additional information such as a home or away dummy, audience size, or team identifiers have no significant influence on the prediction of the match outcome cannot be rejected in a joint F-test; see Appendix A1, Table A.1.
} 
We view a team as being in a loss frame whenever it is behind its reference point. Note that a team that expects to win is in a loss frame at the beginning of a match because a match starts off with a tie. However, probably even a clear favorite does not feel to be in a loss frame if he is not ahead after a few minutes of play. Indeed, in matches with at least one goal, on average the first goal is not scored until 31 minutes of play in the BL and until 32 minutes in the PL. Since we will show that the reference point is a significant predictor for the players' behavior, our implicit assumption that a team is in a loss frame in early minutes, favors the null hypothesis that we test (and reject) in this paper. Table 1 shows that a team is in a loss frame in a little less than a third of the time; this magnitude is very similar in the BL and the

PL.

\subsection{Data preparation}

We observe match events on a minute-by-minute basis, so we cannot infer the chronology of events within a minute of play. In particular, we cannot determine whether a goal preceded a card within the same minute or vice versa. However, a card and a goal in the same minute is a very rare event. In the BL, we observe a goal and a card in the same minute in 37 out of 563'988 minutes only; in the PL, this happened in 67 out of 585'178 minutes. In preparing the data for our analysis, we apply the rule that goals follow after cards. ${ }^{10}$

Moreover, it is possible that more than one card is shown to players of the same team within the same minute. Multiple cards in a given minute are however very rare events; less than 1 percent of all cards fall into this category. ${ }^{11}$ In this paper, we are interested in an estimator for the increase in the probability of being assigned cards as a function of whether a team is in the loss frame or not in a certain minute of the match. Thus, we use a linear probability model (described in more detail below) which yields the best linear unbiased estimator of this probability. This binary response estimation framework

\footnotetext{
${ }^{10}$ Our results do not depend on this assumption. If we assume that cards follow goals, our main regression results in Table 2 remain unchanged. The coefficients on "Loss frame" in regressions (3), (4), (7), and (8) are then given by $0.0049,0.0048,0.0052$, and 0.0052 , respectively, and all these coefficients are highly significant at the 1 percent level.

${ }^{11}$ In the BL, we observe 88 minutes in which two yellow cards were assigned and a single minute in which 3 yellow cards were assigned. There is no minute with two or more red cards. In the PL, we observe 109 minutes in which two yellow cards were assigned and 8 minutes in which 3 yellow cards were assigned. There is a single minute with two red cards.
} 
treats minutes of the match in which more than one card was shown to players in the same team identical to minutes in which only one card was shown to players in the same team. ${ }^{12}$

Finally, we could have multiple goals in the same minute. In these cases, we use the net change in the teams' positions, i.e., both teams scoring in the same minute does not alter the loss frame for either team. Again, this is a very rare event and happened only once in the BL and once in the PL.

\subsection{Estimation equation}

To estimate the influence of the expected match outcome on individual players' behaviors, we specify the following estimation equation.

$$
\operatorname{card}_{i t m}=c+\text { lossframe }{ }_{i t m}^{\prime} \times \beta_{1}+X_{i t m}^{\prime} \times \beta_{2}+\varepsilon_{i t m}
$$

where $\operatorname{card}_{i t m}$ is an indicator variable that takes on value 1 if there is at least one card in match $i$ for

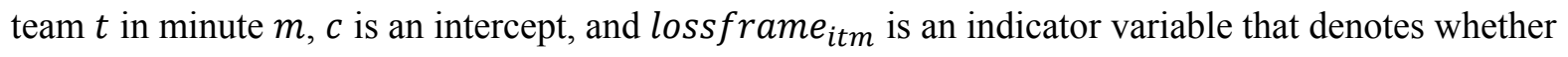
team $t$ was in a loss frame, i.e. whether it lacked behind the expected match outcome in match $i$ in minute $m . X^{\prime}{ }_{i t m}$ contains a set of control variables. For instance, we include minute-of-play dummy variables (ranging from the first to the second-last minute of play) to account for time effects. ${ }^{13}$ In addition, we control for the state of the match by including dummy variables on goal differences. We account for being one goal ahead or behind, two goals ahead or behind, and three or more goals ahead or behind. ${ }^{14}$ Tie serves as the omitted category.

In estimation equation (1), unobserved factors such as contestedness, weather conditions, audience size, referees, location, or season could influence both the loss frame and the probability of seeing a card. One can think of many different mechanisms by which third factors could have a joint

\footnotetext{
${ }^{12}$ Multiple cards are so rare that the assumptions of poisson or negative binomial count data estimation models - an alternative to our binary response modeling approach - are not met. While zero-inflated count data models might fare better at first glance, these models do not apply in our case either: they assume that the excess amount of zero observations are generated by a separate process from the other values, thus not capturing our underlying behavioral assumptions.

${ }^{13}$ A player who receives a yellow card needs to be more careful in the remaining match time which implies that the immediate cost of a yellow card is decreasing towards the end of a match. Similarly, a red card more towards the end of the match will leave the other team members in a short-handed position for a shorter time period. Indeed, we find that more cards are assigned towards the end of matches.

${ }^{14}$ Goal differences of more than 3 are very rare events. As a robustness check, in Appendix A2 we provide the results of an alternative specification where we account for the exact goal differences.
} 
effect on the loss frame and the extent to which players breach the rules of the game. For example, bad weather conditions could add randomness to the course of the game (say, because it is difficult to control the ball), meaning that the team that is expected to win is in a loss frame in a larger part of the match than usual. At the same time, bad weather conditions could lead to a large number of assigned cards (say, because it is more difficult not to breach the rules of the game while trying to win a tackle), thus creating a correlation between occurrences of the loss frame and cards. Our panel data allow us to control for these unobserved factors. To do so, we utilize a one-way error component model for the disturbances $\epsilon_{i t m}$, with

$$
\epsilon_{i t m}=\alpha_{i t}+u_{i t m}
$$

In equation (2), $\alpha_{i t}$ denotes a match specific effect for each team. Inserting equation (2) into (1) leads to estimation equation

$$
\operatorname{card}_{i t m}=c+\text { lossframe }{ }_{i t m}^{\prime} \times \beta_{1}+X^{\prime}{ }_{i t m} \times \beta_{2}+\alpha_{i t}+u_{i t m}
$$

which enables us to consistently estimate $\beta_{1}$, the effect of the loss frame on behavior.

Note that, since we are interested in the behavioral response of the players of a team that is either in a loss frame or not, each match is included twice in our sample: once from the perspective of the home team, and once from the perspective of the away team. This also accounts for possible effects of playing at home or away. Hence, equation (3) does not only account for match but also for team specific effects. Since this procedure introduces interdependence across match observations, we estimate heteroskedasticity-robust standard errors that are adjusted for clustering on the match level.

\section{Results}

Regressions (1) to (4) in Table 2 display our main results from the BL. The dependent variable in regressions (1) and (3) are all cards assigned (yellow and red). The dependent variable in regressions (2) and (4) are yellow cards only. Regressions (1) and (2) control for goal differences and for time effects only. Regressions (3) and (4) show our main result, because these regressions include the dummy variable "Loss frame" that indicates whether a team is behind the expected match outcome or not. 


\section{Table 2: Estimation results}

German Bundesliga (BL)

English Premier League (PL)

\begin{tabular}{|c|c|c|c|c|c|c|c|c|}
\hline Variable & $\begin{array}{l}\text { card } \\
(1)\end{array}$ & $\begin{array}{c}\text { yellow card } \\
\text { (2) }\end{array}$ & $\begin{array}{l}\text { card } \\
(3)\end{array}$ & $\begin{array}{c}\text { yellow card } \\
\text { (4) }\end{array}$ & $\begin{array}{l}\text { card } \\
(5)\end{array}$ & $\begin{array}{c}\text { yellow card } \\
\text { (6) }\end{array}$ & $\begin{array}{l}\text { card } \\
(7)\end{array}$ & $\begin{array}{c}\text { yellow card } \\
(8)\end{array}$ \\
\hline Goal $\Delta+3^{+}$ & $\begin{array}{c}-0.0163 * * * \\
(0.000)\end{array}$ & $\begin{array}{c}-0.0154 * * * \\
(0.000)\end{array}$ & $\begin{array}{c}-0.0126 * * * \\
(0.000)\end{array}$ & $\begin{array}{c}-0.0118 * * * \\
(0.000)\end{array}$ & $\begin{array}{c}-0.0097 * * * \\
(0.000)\end{array}$ & $\begin{array}{c}-0.0111 * * * \\
(0.000)\end{array}$ & $\begin{array}{c}-0.0058 * * * \\
(0.007)\end{array}$ & $\begin{array}{c}-0.0072 * * * \\
(0.000)\end{array}$ \\
\hline Goal $\Delta+2$ & $\begin{array}{c}-0.0024 * * \\
(0.018)\end{array}$ & $\begin{array}{c}-0.0020 * * \\
(0.050)\end{array}$ & $\begin{array}{l}0.0014 \\
(0.229)\end{array}$ & $\begin{array}{l}0.0017 \\
(0.123)\end{array}$ & $\begin{array}{c}-0.0028 * * * \\
(0.001)\end{array}$ & $\begin{array}{c}-0.0027 * * * \\
(0.002)\end{array}$ & $\begin{array}{l}0.0006 \\
(0.530)\end{array}$ & $\begin{array}{l}0.0008 \\
(0.431)\end{array}$ \\
\hline Goal $\Delta+1$ & $\begin{array}{l}0.0011 \\
(0.132)\end{array}$ & $\begin{array}{c}0.0012 * \\
(0.091)\end{array}$ & $\begin{array}{c}0.0045^{* * *} \\
(0.000)\end{array}$ & $\begin{array}{c}0.0045^{* * *} \\
(0.000)\end{array}$ & $\begin{array}{c}0.0015 * * \\
(0.012)\end{array}$ & $\begin{array}{c}0.0015 * * \\
(0.012)\end{array}$ & $\begin{array}{c}0.0047 * * * \\
(0.000)\end{array}$ & $\begin{array}{c}0.0047 * * * \\
(0.000)\end{array}$ \\
\hline Goal $\Delta-1$ & $\begin{array}{c}0.0036 * * * \\
(0.000)\end{array}$ & $\begin{array}{c}0.0033 * * * \\
(0.000)\end{array}$ & $\begin{array}{c}0.0031 * * * \\
(0.000)\end{array}$ & $\begin{array}{c}0.0028 * * * \\
(0.000)\end{array}$ & $\begin{array}{c}0.0014 * * \\
(0.032)\end{array}$ & $\begin{array}{c}0.0014 * * \\
(0.031)\end{array}$ & $\begin{array}{l}0.0007 \\
(0.302)\end{array}$ & $\begin{array}{l}0.0006 \\
(0.304)\end{array}$ \\
\hline Goal $\Delta-2$ & $\begin{array}{l}-0.0006 \\
(0.591)\end{array}$ & $\begin{array}{l}-0.0003 \\
(0.798)\end{array}$ & $\begin{array}{l}-0.0016 \\
(0.160)\end{array}$ & $\begin{array}{l}-0.0012 \\
(0.290)\end{array}$ & $\begin{array}{l}0.0009 \\
(0.411)\end{array}$ & $\begin{array}{l}0.0010 \\
(0.367)\end{array}$ & $\begin{array}{l}0.0001 \\
(0.921)\end{array}$ & $\begin{array}{l}0.0003 \\
(0.776)\end{array}$ \\
\hline Goal $\Delta-3^{+}$ & $\begin{array}{c}-0.0115 * * * \\
(0.000)\end{array}$ & $\begin{array}{c}-0.0101 * * * \\
(0.001)\end{array}$ & $\begin{array}{c}-0.0125 * * * \\
(0.000)\end{array}$ & $\begin{array}{c}-0.0108 * * * \\
(0.001)\end{array}$ & $\begin{array}{c}-0.0091 * * * \\
(0.002)\end{array}$ & $\begin{array}{c}-0.0080 * * * \\
(0.004)\end{array}$ & $\begin{array}{c}-0.0078 * * * \\
(0.006)\end{array}$ & $\begin{array}{c}-0.0068 * * * \\
(0.012)\end{array}$ \\
\hline Loss frame & - & - & $\begin{array}{c}0.0050 * * * \\
(0.000)\end{array}$ & $\begin{array}{c}0.0049 * * * \\
(0.000)\end{array}$ & - & - & $\begin{array}{c}0.0051 * * * \\
(0.000)\end{array}$ & $\begin{array}{c}0.0051^{* * *} \\
(0.000)\end{array}$ \\
\hline Minute dummies & yes & yes & yes & yes & yes & yes & yes & yes \\
\hline Constant & $\begin{array}{c}-0.0139 * * \\
(0.042)\end{array}$ & $\begin{array}{c}-0.0127 * \\
(0.063)\end{array}$ & $\begin{array}{c}-0.0149 * * \\
(0.032)\end{array}$ & $\begin{array}{c}-0.0138 * \\
(0.052)\end{array}$ & $\begin{array}{l}0.1825 \\
(0.207)\end{array}$ & $\begin{array}{l}0.1197 \\
(0.357)\end{array}$ & $\begin{array}{l}0.1804 \\
(0.212)\end{array}$ & $\begin{array}{l}0.1176 \\
(0.365)\end{array}$ \\
\hline$R^{2}$ (overall) & 0.0028 & 0.0026 & 0.0024 & 0.0023 & 0.0027 & 0.0026 & 0.0020 & 0.0019 \\
\hline \# observations & $563^{\prime} 988$ & $563^{\prime} 988$ & $563^{\prime} 988$ & $563^{\prime} 988$ & $585^{\prime} 178$ & $585^{\prime} 178$ & $585^{\prime} 178$ & $585^{\prime} 178$ \\
\hline \# groups & $6^{\prime} 120$ & $6^{\prime} 120$ & $6^{\prime} 120$ & $6^{\prime} 120$ & $6^{\prime} 080$ & $6^{\prime} 080$ & $6^{\prime} 080$ & $6^{\prime} 080$ \\
\hline
\end{tabular}

Notes: The table shows the results of estimation equation (3). The dependent variable in regressions (1), (3), (5), and (7) are all cards assigned, in regressions (2), (4), (6), and (8) yellow cards only. The numbers in brackets show p-values, based on robust standard errors, clustering on the match level. The number of "groups" is twice the number of matches as we view each match from both teams" perspective. Goal $\Delta$ indicates goal differences; $3^{+}$denotes " 3 or larger." ***, **, and * indicates significance at the 1,5 , and 10 percent level, respectively. 
Regression (1) shows the effect of the state of the match on the probability that a player of a team is assigned a yellow or red card. The omitted category is a tie. If the goal difference is three or larger, i.e., if the final outcome of the match is by and large decided, then there are significantly fewer cards. ${ }^{15}$ This effect is indicated by the negative and highly significant coefficients of Goal $\Delta+3^{+}$and Goal $\Delta-3^{+}$. Since it is unlikely that a team will turn the match around, players might reduce their efforts, take fewer risks, or play less aggressively, which all results in fewer fouls and thus fewer cards. Even if a team is ahead only by two goals (Goal $\Delta+2)$, we observe a significant but smaller reduction of cards; the effect for a team that is two goals behind is, however, very small and insignificant. For states of the match where the final outcome is relatively open, we find that being behind by one goal (Goal $\Delta-1)$ increases the probability of a card significantly relative to a tie. Regression (2) shows that the pattern is almost identical if we look at yellow cards only, i.e., the results are not driven by the inclusion of (the very rare) red cards. We also control for minute fixed effects in all regressions because there is a time trend in that more cards are assigned towards the end of a match (not shown in Table 2).

To address the question that is raised in this paper, regression (3) includes the dummy variable "Loss frame" that equals 1 if a team is in a loss frame and 0 otherwise. Regression (3) shows our first main result: the coefficient of the dummy is positive, large, and highly significant. This finding reveals that the players of a team are more likely to receive a card when they are behind the expected match outcome. Notice that the result is derived while we control for the state of the match. For example, the players of a team are more likely to receive a card when they are behind by one goal, but they are even more likely to receive a card when they are unexpectedly behind. The size of the coefficient of the loss frame dummy is 0.0050 , which indicates an increase in the probability of seeing a card by more than 20 percent (recall that the baseline probability of receiving a card is 0.024 ). Regression (4) shows that the result holds if we consider yellow cards only. We summarize our finding as follows.

\footnotetext{
${ }^{15}$ Indeed, in every single match in both the BL and the PL, when a team was ahead by three goals at some point in time, this team ultimately won the match.
} 
Result 1: The players of a team in the German Bundesliga receive significantly more cards if the team is behind the expected match outcome. While controlling for the state of the match, being in a loss frame increases the probability of receiving a card in a given minute by more than 20 percent.

Table 2 also displays the results from the PL. Regressions (5) to (8) are analogous to regressions (1) to (4), and they confirm our main findings from the BL. In regression (5), we again find that significantly fewer cards are assigned if the goal difference is three or larger. Also, if a team is two goals ahead we again observe a significant reduction of cards; the effect for a team that is two goals behind is again very small and insignificant. We also observe again that being behind by one goal increases the probability of a card significantly relative to a tie; the effect of being one goal ahead is now also significant. Regression (6) shows that this pattern holds if we consider yellow cards only.

Importantly, regression (7) includes the dummy variable "Loss frame." As in the BL, its coefficient is positive, large, and highly significant. This finding shows that also in the PL, the players of a team are more likely to receive a card when they are behind the expected match outcome ${ }^{16}$ The size of the coefficient is 0.0051 , which indicates an increase in the probability of seeing a card by 30 percent (recall that in the PL the baseline probability of receiving a card is 0.017 ). The effect of being in a loss frame on the players' behavior is thus even stronger in the PL than in the BL. Regression (8) shows that the result again holds if we consider yellow cards only. We summarize our finding as follows.

Result 2: The players of a team in the English Premier League receive significantly more cards if the team is behind the expected match outcome. While controlling for the state of the match, being in a loss frame increases the probability of receiving a card in a given minute by 30 percent.

The above analysis demonstrates that the players' behavior in two independent samples measured by assigned cards - changes depending on whether or not their team is behind the expected

\footnotetext{
${ }^{16}$ In contrast to the BL, however, once we control for the loss frame we do not find that teams that are behind by one goal receive significantly more cards. Hence, a team in the PL receives more cards only if it is unexpectedly behind by one goal.
} 
match outcome. Results 1 and 2 thus both reject the null hypothesis that the reference point that is given by the ex-ante expected match outcome does not affect the players' behavior. ${ }^{17}$

\section{Conclusion}

A solid understanding of the determinants of reference points and of the impact of reference points on behavior is important not only for organizational and managerial decision making, but for economics in general. Examples include the impact of reference-dependent preferences for worker morale and effort choices, consumer goods pricing, and incomplete contracting.

We add to the existing knowledge in this paper by providing an analysis of two unique, naturallyoccurring panel field data sets that provide rare opportunities to test the relevance of expectation-based reference points in the field. We show that professional soccer players' behavior during matches depends significantly on whether or not the team is behind the expected match outcome. The expected match outcome is measured by pre-play betting odds on match outcomes of large professional bookmakers. Our behavioral measure is the players' breaches of the rules of the game, measured by the cards official referees assign. We find that if a team is behind the expected match outcome, the players of this team see significantly and sizably more cards, with an increase between 20 and 30 percent, compared to match situations in which the team is not behind its expectation. These findings lend support to the idea that expectations shape reference points and that people's behavior depends on how a given outcome contrasts with this reference point.

Moreover, our data clearly show that the reference-dependent behavior neither disappears with experience, competition, nor high-stakes, because our results are derived in data sets that come from professional, experienced subjects who act in their natural environment, which is a fiercely competitive, high-stakes industry.

\footnotetext{
${ }^{17}$ We replicate our results in Appendix A2 using regressions where we control for goal differences up to the maximum of 9 and 7 in the BL and PL, respectively. The loss frame dummy remains significant at the 1 per cent in the PL and at the 5 percent level in the BL. In the appendix, we also discuss a possible multicollinearity problem in the specification with the full set of goal difference dummies, which might cause the slight drop in the significance level in the BL.
} 


\section{References}

Abeler, Johannes, Armin Falk, Lorenz Goette and David Huffman. 2011. „Reference Points and Effort Provision.“ American Economic Review. 101(2): 470-92.

Bell, David E. 1985. "Disappointment in Decision Making under Uncertainty", Operations Research, 33: $1-27$.

Bewley, Truman F. 1999. "Why Wages Don't Fall During a Recession”, Harvard University Press.

Camerer, Colin, Linda Babcock, George Loewenstein and Richard Thaler. 1997. "Labor Supply of New York City Cabdrivers: One Day at a Time.” Quarterly Journal of Economics, 112 (2): 40741.

Card, David and Gordon Dahl. 2011. "Family Violence and Football: The Effect of Unexpected Emotional Cues on Violent Behavior.” Quarterly Journal of Economics, 126(1): 103-43.

Chiappori, Pierre-Andre, Steven Levitt and Timothy Groseclose. 2002. "Testing Mixed-Strategy Equilibria When Players Are Heterogenous: The Case of Penalty Kicks in Soccer.” American Economic Review, 92(4): 1138-51.

Choi, Syngjoo, Raymond Fisman, Douglas Gale, and Shachar Kariv. 2007. "Consistency and Heterogeneity of Individual Behavior under Uncertainty.” American Economic Review, 97(5): $1921-38$.

Crawford, Vincent P. and Juanjuan Meng. 2011. “New York City Cabdrivers’ Labor Supply Revisited: Reference-Dependent Preferences with Rational-Expectations Targets for Hours and Income." American Economic Review, 101(5): 1912-32.

Deloitte. 2009. “Annual Review of Football Finance”, Deloitte, Sports Business Group.

Dohmen, Thomas J. 2008. „Do Professionals Choke Under Pressure?“ Journal of Economic Behavior and Organization, 65: 636-53.

Falk, Armin and James J. Heckman. 2009. "Lab Experiments Are a Major Source of Knowledge in the Social Sciences." Science, Vol. 326(5952): 535-38. 
Fehr, Ernst and Lorenz Götte 2007. "Do Workers Work more when Wages are High? Evidence from a Randomized Field Experiment.” American Economic Review, 97(1): 298-317.

Garicano, Luis, Ignacio Palacios- Huerta and Canice Prendergast. 2005. "Favoritism under Social Pressure." Review of Economics and Statistics, 87 (2): 208-16.

Gill, David and Victoria Prowse. 2012. “A Structural Analysis of Disappointment Aversion in a Real Effort Competition", American Economic Review, 102(1): 469-503.

Gul, Faruk. 1991. “A Theory of Disappointment Aversion”, Econometrica, 59 (3): 667-86.

Hart, Oliver, and John Moore. 2008. "Contracts as Reference Points”, Quarterly Journal of Economics, 123(1): 1-48.

Heidhues, Paul, and Botond Köszegi. 2008. “Competition and Price Variation when Consumers Are Loss Averse.” American Economic Review, 98(4): 1245-68.

Herweg, Fabian, Daniel Müller and Philipp Weinschenk. 2010. "Binary Payment Schemes: Moral Hazard and Loss Aversion.” American Economic Review, 100(5): 2451-77.

Kahn, Lawrence M. 2000. “The Sports Business as a Labor Market Laboratory”, Journal of Economic Perspectives, 14 (3): 75-94.

Kahneman, Daniel and Amos Tversky. 1979. "Prospect Theory: An Analysis of Decision Under Risk." Econometrica, 47 (2): 263-91.

Kocher, Martin G. and Matthias Sutter. 2004. "Favoritism of Agents - The Case of Referee's Home Bias.” Journal of Economic Psychology, 25: 461-69.

Kocher, Martin G., Marc V. Lenz, and Matthias Sutter. Forthcoming. "Psychological pressure in competitive environments: New evidence from randomized natural experiments." Management Science.

Köszegi, Botond and Matthew Rabin. 2006. "A Model of Reference-Dependent Preferences." Quarterly Journal of Economics, 121 (4): 1133-65.

Köszegi, Botond and Matthew Rabin. 2007. "Reference-Dependent Risk Attitudes.” American Economic Review, 97 (4): 1047-73. 
Köszegi, Botond and Matthew Rabin. 2009. "Reference-Dependent Consumption Plans.” American Economic Review, 99 (3): 909-36.

Levitt Steven. D. and John A. List. 2007. "What do Laboratory Experiments Measuring Social Preferences Reveal About the Real World?” Journal of Economic Perspectives, Vol. 21(2): 15374.

Loomes, Graham and Robert Sugden. 1986. "Disappointment and Dynamic Consistency in Choice under Uncertainty", Review of Economic Studies, 53 (2): 271-82.

Loomes, Graham and Robert Sugden. 1987. “Testing for Regret and Disappointment in Choice under Uncertainty", Economic Journal, 97: 118-29.

Marzilli Ericson, Keith M. and Andreas Fuster. 2011. "Expectations as Endowments: Evidence on Reference-Dependent Preferences from Exchange and Valuation Experiments." Quarterly Journal of Economics, 126: 1879-907.

Mas, Alexandre. 2006. "Pay, reference points, and police performance”, Quarterly Journal of Economics, 121(3): 783-821.

Ockenfels, Axel, Dirk Sliwka, and Peter Werner. 2010. "Bonus Payments and Reference Points Violations", IZA Discussion Paper No. 4795.

Pope, Devin G. and Maurice E. Schweitzer. 2011.”Is Tiger Woods Loss Averse? Persistent Bias in the Face of Experience, Competition, and High Stakes.” American Economic Review. 101(1): 129-57.

Post, Thierry, Martin J. van den Assem, Guido Baltussen and Richard H. Thaler. 2008. "Deal or No Deal? Decision Making under Risk in a Large-Payoff Game Show”. American Economic Review, 98(1): 38-71.

Price, Joseph and Justin Wolfers. 2010. "Racial Discrimination among NBA Referees". Quarterly Journal of Economics, 125(4):1859-87.

Walker, Marc and John Wooders. 2001. "Minimax Play at Wimbledon.” American Economic Review, 91(5): 1521-38. 


\section{Appendix}

\section{A1. Multinomial logit model}

Professional bookmakers have a strong incentive to incorporate all available information into their odds.

To check for market efficiency, we apply a multinomial logit model to test for the predictive power of additional, observable match characteristics in our samples from the BL and the PL. Table A.1 shows that F-tests of joint significance of a home dummy, the audience size, and team identifiers are not significant.

\section{Table A.1: Predicting Match Outcomes}

\section{German Bundesliga (BL) English Premier League (PL)}

\begin{tabular}{|c|c|c|c|c|}
\hline Variable & & & & \\
\hline \multicolumn{5}{|l|}{ Match Outcome $=3$ points (win): } \\
\hline Implicit loss probability & $\begin{array}{l}2.147 \\
(0.186)\end{array}$ & $\begin{array}{c}1.332 \\
(0.440)\end{array}$ & $\begin{array}{l}-1.446 \\
(0.299)\end{array}$ & $\begin{array}{l}-1.156 \\
(0.440)\end{array}$ \\
\hline Implicit win probability & $\begin{array}{c}5.837 * * * \\
(0.000)\end{array}$ & $\begin{array}{c}5.009^{* * *} \\
(0.003)\end{array}$ & $\begin{array}{l}2.579^{*} \\
(0.051)\end{array}$ & $\begin{array}{l}2.851^{* *} \\
(0.047)\end{array}$ \\
\hline \multicolumn{5}{|l|}{ Match outcome $=0$ points (loss): } \\
\hline Implicit loss probability & $\begin{array}{c}5.837 * * * \\
(0.000)\end{array}$ & $\begin{array}{c}5.009 * * * \\
(0.003)\end{array}$ & $\begin{array}{l}2.579 * \\
(0.051)\end{array}$ & $\begin{array}{r}2.851^{* *} \\
(0.047)\end{array}$ \\
\hline Implicit win probability & $\begin{array}{c}2.147 \\
(0.186)\end{array}$ & $\begin{array}{l}1.332 \\
(0.440)\end{array}$ & $\begin{array}{l}-1.446 \\
(0.299)\end{array}$ & $\begin{array}{l}-1.156 \\
(0.440)\end{array}$ \\
\hline Home dummy & yes & yes & yes & yes \\
\hline Audience size & yes & yes & yes & yes \\
\hline Team identifiers & - & yes & - & yes \\
\hline F-test home dummy and audience size & $\mathrm{p}=0.439$ & & $\mathrm{p}=1.000$ & \\
\hline $\begin{array}{l}\text { F-test home dummy, audience size, and } \\
\text { team identifiers }\end{array}$ & & $\mathrm{p}=0.253$ & & $\mathrm{p}=0.719$ \\
\hline $\begin{array}{l}\text { Pseudo } \mathrm{R}^{2} \\
\text { \# observations }\end{array}$ & $\begin{array}{l}0.076 \\
6 \\
6\end{array}$ & $\begin{array}{l}0.080 \\
6^{\prime} 120\end{array}$ & $\begin{array}{l}0.097 \\
6^{\prime} 080\end{array}$ & $\begin{array}{l}0.102 \\
6^{\prime} 080\end{array}$ \\
\hline
\end{tabular}

Notes: Displayed are estimation results from a multinomial logit model for the equation

Match outcome $=($ implicit loss probability $) \times \beta+($ implicit win probability $) \times \pi+\varepsilon$. Tied matches $(=1$ point $)$ served as the base outcome. The numbers in brackets show p-values. ${ }^{* *},{ }^{* *}$, and $*$ indicates significance at the 1,5 , and 10 percent level, respectively. 


\section{A2. Estimation results with full set of goal differences}

In the BL, goal differences of 4 or more are observed in 0.9 percent of the minutes, but in only 0.8 percent of the minutes in the PL. Thus, we only control for being one goal ahead or behind, two goals ahead or behind and three or more goals ahead or behind in our main specifications that are reported in Table 2. As a robustness check, we reproduce the estimations in this appendix with a full set of goal difference dummies to account for the exact goal differences which range up to 9 in the BL and up to 7 in the PL. Table A. 2 shows that the loss frame dummies in these estimations remain significant in both the BL and the PL.

The absolute magnitude of the loss frame coefficient decreases in both leagues, however. Moreover, while the significance level remains at 1 percent in the PL, it slightly drops from 1 percent to 5 percent in the BL. The reason for the biased and less precise estimates of the loss frame dummy is the collinearity problem that arises because all goal difference dummies of 4 or higher are very highly correlated with the loss frame dummy. More specifically, if a team is more than 3 goals ahead, it is never in the loss frame, i.e., the loss frame dummy is zero, thus implying a perfect negative correlation; in turn, if a team is more than 3 goals behind, it is currently losing the match and in the large majority of cases this team was also expected to lose the match, i.e., it was not in a loss frame in this situation, thus implying a very high negative correlation. 
Table A.2: Estimation results with full set of goal differences

\begin{tabular}{|c|c|c|c|c|}
\hline & \multicolumn{2}{|c|}{ German Bundesliga (BL) } & \multicolumn{2}{|c|}{ English Premier League (PL) } \\
\hline Variable & $\begin{array}{l}\text { card } \\
(1)\end{array}$ & $\begin{array}{c}\text { yellow card } \\
(2)\end{array}$ & $\begin{array}{l}\text { card } \\
(3)\end{array}$ & $\begin{array}{c}\text { yellow card } \\
(4)\end{array}$ \\
\hline Goal $\Delta+9$ & $\begin{array}{c}-0.0593 * * * \\
(0.000)\end{array}$ & $\begin{array}{c}-0.0570 * * * \\
(0.000)\end{array}$ & - & - \\
\hline Goal $\Delta+8$ & $\begin{array}{c}-0.0462 * * * \\
(0.000)\end{array}$ & $\begin{array}{c}-0.0454 * * * \\
(0.000)\end{array}$ & - & - \\
\hline Goal $\Delta+7$ & $\begin{array}{c}-0.0375 * * * \\
(0.000)\end{array}$ & $\begin{array}{c}-0.0363 * * * \\
(0.000)\end{array}$ & $\begin{array}{c}-0.0270 * * * \\
(0.000)\end{array}$ & $\begin{array}{c}-0.0263 * * * \\
(0.000)\end{array}$ \\
\hline Goal $\Delta+6$ & $\begin{array}{c}-0.0253 * * * \\
(0.001)\end{array}$ & $\begin{array}{c}-0.0242 * * * \\
(0.002)\end{array}$ & $\begin{array}{r}-0.0003 \\
(0.973)\end{array}$ & $\begin{array}{l}-0.0003 \\
(0.979)\end{array}$ \\
\hline Goal $\Delta+5$ & $\begin{array}{c}-0.0193 * * * \\
(0.000)\end{array}$ & $\begin{array}{c}-0.0182^{* * * *} \\
(0.000)\end{array}$ & $\begin{array}{c}-0.0150 * * * \\
(0.000)\end{array}$ & $\begin{array}{c}-0.0150 * * * \\
(0.000)\end{array}$ \\
\hline Goal $\Delta+4$ & $\begin{array}{c}-0.0168 * * * \\
(0.000)\end{array}$ & $\begin{array}{c}-0.0159 * * * \\
(0.000)\end{array}$ & $\begin{array}{c}-0.0081 * * * \\
(0.001)\end{array}$ & $\begin{array}{c}-0.0101 * * * \\
(0.000)\end{array}$ \\
\hline Goal $\Delta+3$ & $\begin{array}{c}-0.0097 * * * \\
(0.000)\end{array}$ & $\begin{array}{c}-0.0092 * * * \\
(0.000)\end{array}$ & $\begin{array}{c}-0.0073 * * * \\
(0.000)\end{array}$ & $\begin{array}{c}-0.0080 * * * \\
(0.000)\end{array}$ \\
\hline Goal $\Delta+2$ & $\begin{array}{c}-0.0021 \\
(0.104)\end{array}$ & $\begin{array}{c}-0.0016 \\
(0.217)\end{array}$ & $\begin{array}{c}-0.0014 \\
(0.214)\end{array}$ & $\begin{array}{l}-0.0015 \\
(0.196)\end{array}$ \\
\hline Goal $\Delta+1$ & $\begin{array}{c}0.0021 * * \\
(0.048)\end{array}$ & $\begin{array}{c}0.0022 * * \\
(0.031)\end{array}$ & $\begin{array}{c}0.0033^{* * *} \\
(0.000)\end{array}$ & $\begin{array}{c}0.0032 * * * \\
(0.000)\end{array}$ \\
\hline Goal $\Delta-1$ & $\begin{array}{c}0.0017 * * \\
(0.033)\end{array}$ & $\begin{array}{l}0.0015 * \\
(0.057)\end{array}$ & $\begin{array}{l}0.0002 \\
(0.710)\end{array}$ & $\begin{array}{l}0.0002 \\
(0.714)\end{array}$ \\
\hline Goal $\Delta-2$ & $\begin{array}{c}-0.0043 * * * \\
(0.000)\end{array}$ & $\begin{array}{c}-0.0038 * * * \\
(0.001)\end{array}$ & $\begin{array}{l}-0.0007 \\
(0.524)\end{array}$ & $\begin{array}{l}-0.0005 \\
(0.647)\end{array}$ \\
\hline Goal $\Delta-3$ & $\begin{array}{c}-0.0117 * * * \\
(0.000)\end{array}$ & $\begin{array}{c}-0.0112 * * * \\
(0.000)\end{array}$ & $\begin{array}{c}-0.0033^{*} \\
(0.076)\end{array}$ & $\begin{array}{c}-0.0030 * \\
(0.095)\end{array}$ \\
\hline Goal $\Delta-4$ & $\begin{array}{c}-0.0179 * * * \\
(0.000)\end{array}$ & $\begin{array}{c}-0.0159 * * * \\
(0.000)\end{array}$ & $\begin{array}{c}-0.0091 * * * \\
(0.003)\end{array}$ & $\begin{array}{c}-0.0079 * * * \\
(0.007)\end{array}$ \\
\hline Goal $\Delta-5$ & $\begin{array}{c}-0.0114^{*} \\
(0.080)\end{array}$ & $\begin{array}{l}-0.0104 \\
(0.116)\end{array}$ & $\begin{array}{c}-0.0139 * * * \\
(0.008)\end{array}$ & $\begin{array}{c}-0.0124 * * \\
(0.016)\end{array}$ \\
\hline Goal $\Delta-6$ & $\begin{array}{c}-0.0206^{* *} \\
(0.032)\end{array}$ & $\begin{array}{c}-0.0172 * * \\
(0.047)\end{array}$ & $\begin{array}{l}0.0007 \\
(0.957)\end{array}$ & $\begin{array}{r}-0.0041 \\
(0.674)\end{array}$ \\
\hline Goal $\Delta-7$ & $\begin{array}{c}-0.0388 * * * \\
(0.000)\end{array}$ & $\begin{array}{c}-0.0371 * * * \\
(0.000)\end{array}$ & $\begin{array}{l}0.0203 \\
(0.435)\end{array}$ & $\begin{array}{l}0.0222 \\
(0.378)\end{array}$ \\
\hline Goal $\Delta-8$ & $\begin{array}{c}-0.0479 * * * \\
(0.001)\end{array}$ & $\begin{array}{c}-0.0466^{* * *} \\
(0.001)\end{array}$ & - & - \\
\hline Goal $\Delta-9$ & omitted & omitted & - & - \\
\hline Loss frame & $\begin{array}{c}0.0030 * * \\
(0.012)\end{array}$ & $\begin{array}{c}0.0030 * * \\
(0.012)\end{array}$ & $\begin{array}{c}0.0038 * * * \\
(0.000)\end{array}$ & $\begin{array}{c}0.0036 * * * \\
(0.000)\end{array}$ \\
\hline Minute dummies & yes & yes & yes & yes \\
\hline Constant & $\begin{array}{c}-0.0139 * \\
(0.054)\end{array}$ & $\begin{array}{c}-0.0128 * \\
(0.079)\end{array}$ & $\begin{array}{l}0.1816 \\
(0.208)\end{array}$ & $\begin{array}{l}0.1189 \\
(0.360)\end{array}$ \\
\hline$R^{2}$ (overall) & 0.0026 & 0.0025 & 0.0023 & 0.0022 \\
\hline \# observations & $563^{\prime} 988$ & $563^{\prime} 988$ & $585^{\prime} 178$ & $585^{\prime} 178$ \\
\hline \# groups & $6^{\prime} 120$ & $6^{\prime} 120$ & $6^{\prime} 080$ & $6^{\prime} 080$ \\
\hline
\end{tabular}

Notes: The dependent variable in regressions (1) and (3) are all cards assigned, in regressions (2) and (4) yellow cards only. The maximum goal difference is 9 in the BL and 7 in the PL. The numbers in brackets show p-values, based on robust standard errors, clustering on the match level. The number of "groups" is twice the number of matches as we view each match from both teams' perspective. Goal $\Delta$ indicates goal differences. ${ }^{* *}, * *$, and $*$ indicates significance at the 1,5 , and 10 percent level, respectively. 